\title{
OVERVIEW OF THE OCEANS AND HUMAN HEALTH SPECIAL ISSUE
}

\author{
BY LORA E. FLEMING AND EDWARD LAWS
}

For many years, the scientific community has focused on the negative impacts of humans on the oceans. Recently, with major weather events such as the 2005 hurricane season, as well as the other issues described below, it has become clear that human health is inextricably linked to ocean health, and vice versa. Because of the oceans' vastness and the dependence of an increasing number of humans on the oceans, this inter-relationship between human health and ocean health is shared by all humans and other creatures on Earth (Epstein et al., 1994; Epstein, 1995; Kovats et al., 1998; National Research Council [NRC], 1999; Anonymous, 2001; Knap et al., 2002; Stegeman et al., 2002; Tibbets, 2002; Dewailly, 2002; Pew Oceans Commission, 2003; Tyson et al., 2004; U.S. Commission on Ocean Policy, 2004; Sandifer et al., 2004; Tibbets, 2005; Bowen et al., in press; Fleming et al., in press). To address the complex relationship between the oceans and human health, a new type of interdisciplinary science is needed, one that brings together oceanographic and biomedical scientists, as well as other disciplines. This special issue of Oceanography contains a series of articles and illustrative case studies by an interdisciplinary group of scientists on key issues of oceans and human health.

\section{BACKGROUND}

A significant and increasing proportion of the world's human population now lives within $120 \mathrm{~km}$ of an ocean coast, particularly in subtropical and tropical areas (Knap et al., 2002; Tibbetts, 2002; Bowen et al., this issue). Furthermore, the oceans are an internationally shared resource and an extremely efficient conduit (of pollutants, seafood, weather, and others) among nations. This new per- spective has revealed the global interconnectedness for all humans between their health and that of the oceans.

After the United Nations declared 1998 "the International Year of the Ocean," the associated worldwide activities celebrating the importance of the oceans and their inter-connectedness with humans led to a new focus on the oceans and human health. In particular, scientists and the general public became aware of the potentially positive and negative relationships between human health and the oceans. Specifically, human health can be affected by oceanbased phenomena ranging from extreme weather and global climate change, to microbial and chemical pollution with contamination of the food chain, to harmful algal blooms (HABs).

These negative effects, or risks, serve as warnings with regards to the potential effects of human activities on the oceans, 

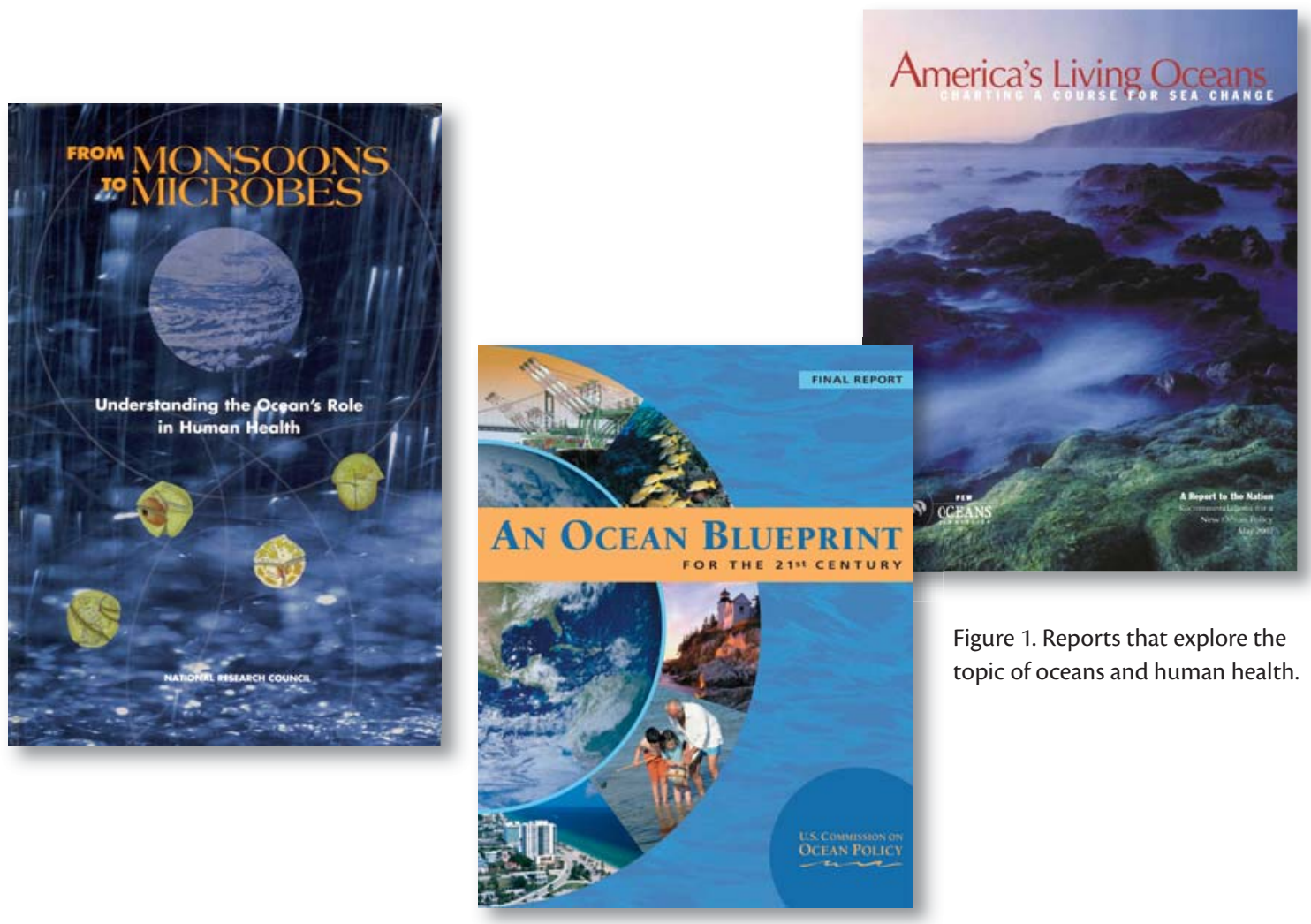

ultimately leading to major effects on human health. At the same time, these potentially negative impacts on human health have led to the development of new tools and scientific discoveries in the areas of natural products (or "drugs from the seas"), marine indicators and probes, marine models of human disease, the protection of the marine food supply, and the development of comprehensive worldwide observing systems that can provide the possibility of control and prevention.

In 1999, the NRC published a seminal document summarizing many of the important issues associated with oceans and human health, From Monsoons to Microbes: Understanding the Oceans Role in Human Health (NRC, 1999). In addition to summarizing the key issues in this area and the current state of knowledge, this document suggested how current and future efforts could be directed so that future health needs and threats to both humans and the oceans could be anticipated and addressed. The NRC document catalyzed a series of reports and other activities on various aspects of oceans and human health.

In 2003, the Pew Oceans Commission released a report entitled, America's Living Ocean: Charting a Course for Sea Change (Pew Oceans Commission, 2003). The Pew Report focused directly on ocean health, but indirectly on human health. The document included recommendations for improved management of the nation's commercial fisheries, establishment of networks of marine reserves in coastal waters, application of strong environmental standards to fish farming, and regulation of cruise ship wastewater discharge (Pew Oceans Commission, 2003).

On September 20, 2004, under Congressional mandate, the U.S. Commis- sion on Ocean Policy issued a report entitled, An Ocean Blueprint for the 21st Century. This report addresses a range of ocean and coastal policy issues and makes 212 recommendations to halt the steady decline of our nation's oceans and coasts (U.S. Commission on Ocean

Lora E. Fleming (Ifleming@med.miami. edu) is Professor, Department of Epidemiology and Public Health, University of Miami School of Medicine, Miami, FL, USA and Co-Director, National Science Foundation (NSF) National Institute of Environmental Health Sciences (NIEHS) Ocean and Human Heath Center, Rosenstiel School of Marine and Atmospheric Sciences, University of Miami, Miami, FL, USA. Edward Laws is Professor and Dean, School of the Coast and Environment, Louisiana State University, Baton Rouge, LA, USA and Director, NSF NIEHS Oceans and Human Health Center, University of Hawaii, Honolulu, HI, USA. 


\section{Oceans and Human Health Centers}

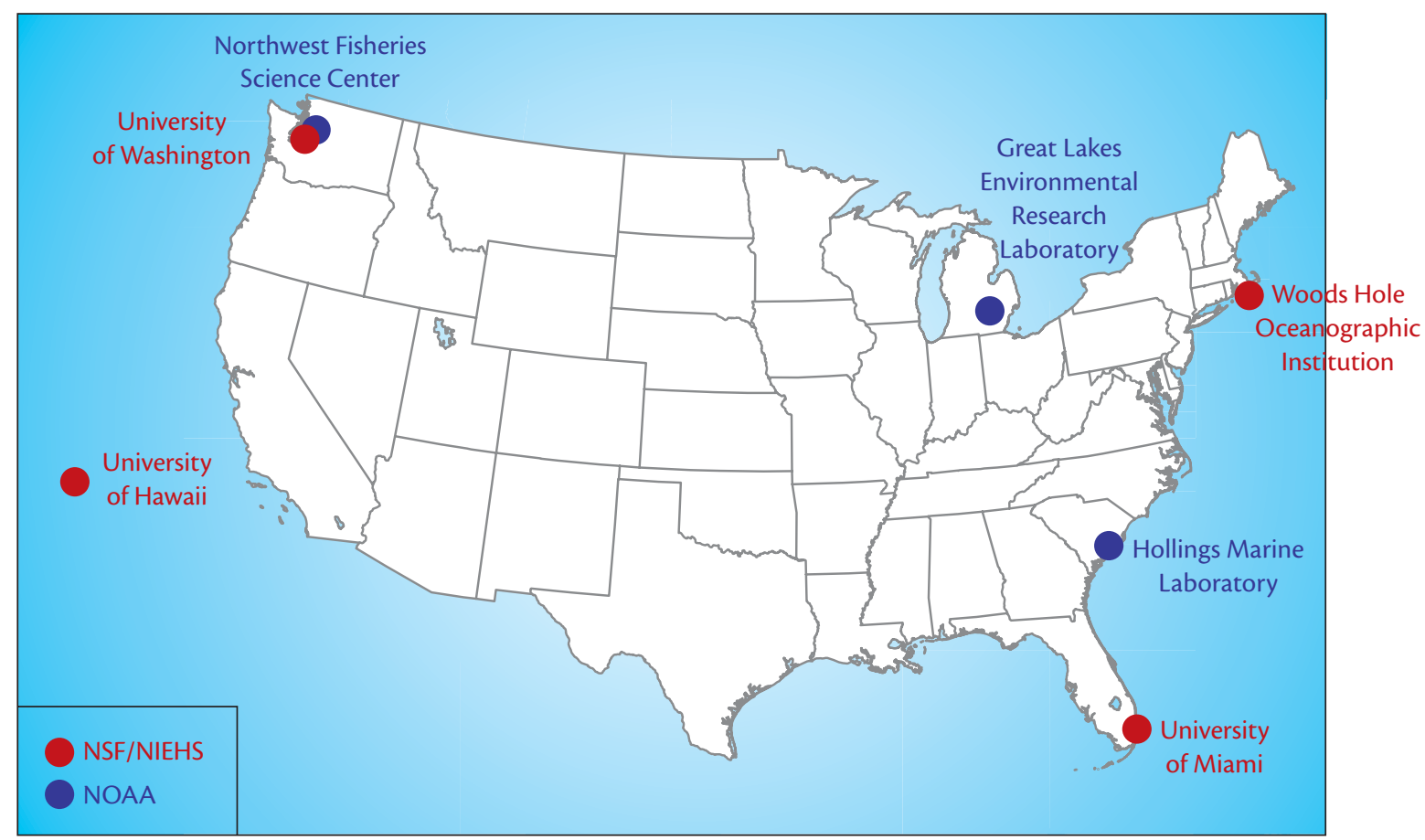

Figure 2. These centers focus on the scientific areas of microbial pollution, HABs, and pharmaceuticals from the seas, as well as outreach and education.

Policy, 2004) (Figure 1).

Finally, in 2004, the U.S. National Science Foundation (NSF) and National Institute of Environmental Health Sciences (NIEHS) collaboratively co-funded four Centers of Oceans and Human Health around the nation (Figure 2) (Anonymous, 2001; Tyson et al., 2004; http://www.whoi.edu/science/cohh/). In addition, the U.S. National Oceanic and Atmospheric Administration (NOAA) directed several of its laboratories to create NOAA Oceans and Human Health Centers (Sandifer et al., 2004; for more information visit http://www.ogp.noaa. gov/mpe/ohi/). Focusing on the scientific areas of microbial pollution, HABs, and pharmaceuticals from the seas, as well as outreach and education, these centers are the foci of exciting interdisciplinary research and training that blend both the traditional biomedical sciences with the oceanographic and other marine sciences. In these centers, physicians and basic scientists work side by side in the quest to understand the risks and benefits posed by the seas and to improve human health.

\section{THE OCEANS AND HUMAN}

\section{HEALTH SPECIAL ISSUE}

This special issue of Oceanography consists of articles and illustrative focused case studies that were selected to give an overview of many of the major issues in this new interdisciplinary area of oceans and human health. The topics selected demonstrate both the breadth of issues and the importance of the interdisciplinary scientific approach. Therefore, the authors include oceanographers, epidemiologists and physicians, toxicologists, economists and sociologists, marine chemists and marine microbiologists, and policy experts and physiologists. Furthermore, as several of the special issue authors note, the subjects covered illustrate both the current and future risks and benefits to human health from the world's oceans.

\section{Risks}

The risks from the seas to human health can be summarized by the two large topic areas: (1) physical risks and (2) pollution.

Current and future physical risks of oceans on human health are the result of the combination of an increasing number of humans moving to coastal areas coupled with the effects of global warming (Figure 3). The increased burden of humans living in coastal areas has led 

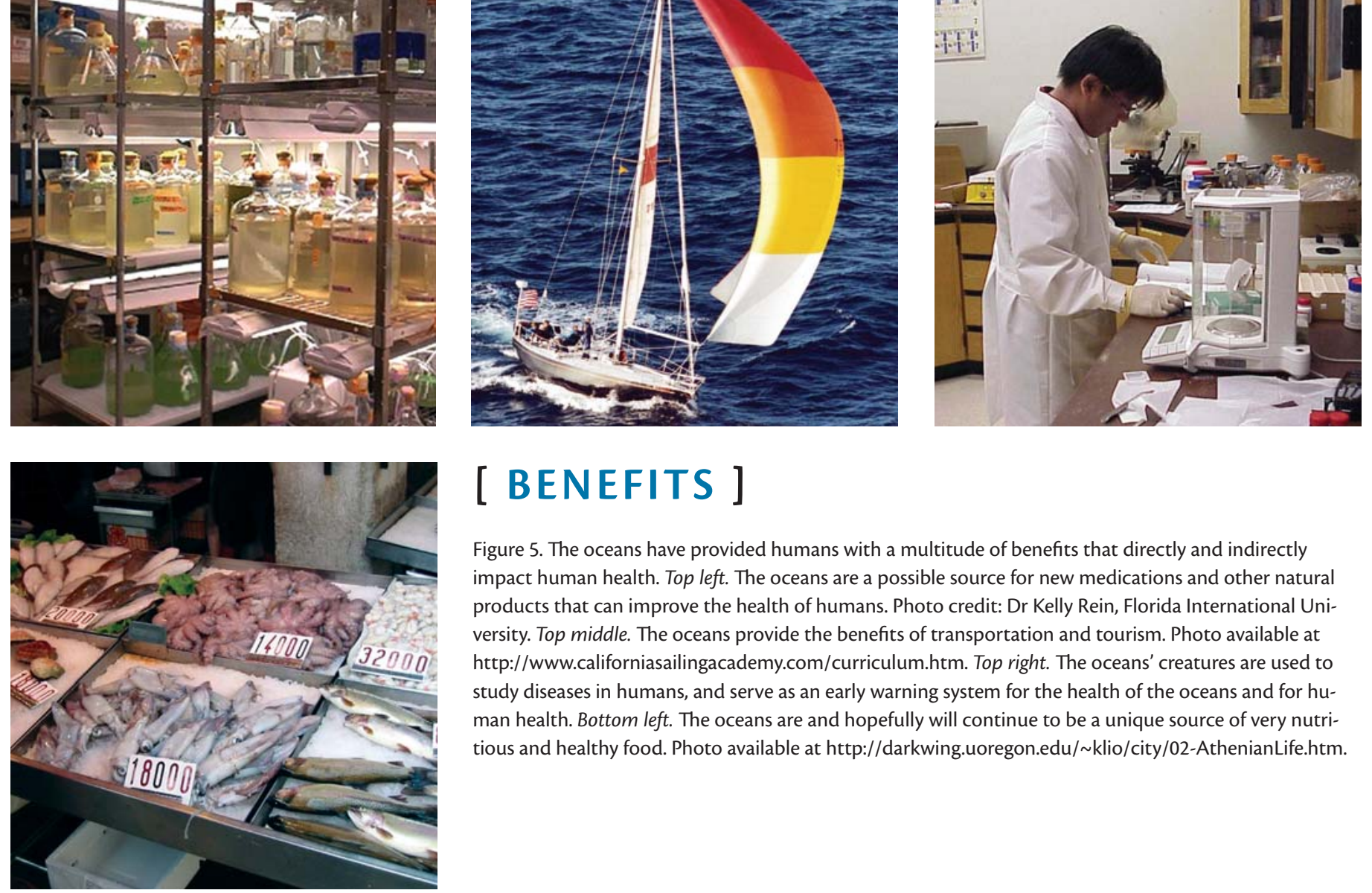

\section{[ BENEFITS ]}

Figure 5. The oceans have provided humans with a multitude of benefits that directly and indirectly impact human health. Top left. The oceans are a possible source for new medications and other natural products that can improve the health of humans. Photo credit: Dr Kelly Rein, Florida International University. Top middle. The oceans provide the benefits of transportation and tourism. Photo available at http://www.californiasailingacademy.com/curriculum.htm. Top right. The oceans' creatures are used to study diseases in humans, and serve as an early warning system for the health of the oceans and for human health. Bottom left. The oceans are and hopefully will continue to be a unique source of very nutritious and healthy food. Photo available at http://darkwing.uoregon.edu/ klio/city/02-AthenianLife.htm.

P50 ES12736); the NIEHS Marine and Freshwater Biomedical Sciences Center at the University of Miami RSMAS (NIEHS P30ES05705); and the National Science Foundation and NIEHS Oceans and Human Health Center at the University of Hawaii (NSF OCE04-32479; NIEHS P50 ES012740). 따

\section{REFERENCES}

Anonymous. 2001. NIEHS-NSF Oceans and Human Health Roundtable. National Institute of Environmental Health Sciences (NIEHS), Research Triangle Park, NC.

Bowen, R.E., H. Harlyn, and M. Depledge, eds. In press. The Ocean and Human Health. Marine Pollution Bulletin (Special Issue).

Dewailly, É., C. Furgal, A. Knap, A., J. Galvin, D. Baden, B. Bowen, M. Depledge, L. Duguay, L. Fleming, T. Ford, F. Moser, R. Owen, W.A. Suk, U. Unluata. 2002. Indicators of ocean and human health. Revue Canadienne de Sante Publique [Canadian Journal of Public Health] 93 (Suppl. 1):S34-38.

Epstein, P.R. 1995. Emerging diseases and ecosystem
instability-New threats to public-health. American Journal of Public Health 85(2):168-172.

Epstein, P.R., T.E. Ford, and R.R. Colwell. 1994. Marine ecosystems. Pp.14-17 in Health and Climate Change, P.R. Epstein, D. Sharp, eds. The Lancet Ltd., London.

Fleming, L.E., K. Broad, A. Clement, É. Dewailly, S. Elmir, A. Knap, S.A. Pomponi, S. Smith, H. Solo Gabriele, and P.J. Walsh. In Press. Emerging public health risks in the marine environment. In: Marine-based Public Health Risk. B. Bowen, H. Halvorson, and M. Depledge, eds., Marine Pollution Bulletin.

Knap, A., É. Dewailly, C. Furgal, J. Galvin, D. Baden, B. Bowen, M. Depledge, L. Duguy, L.E. Fleming, T. Ford, F. Moser, R. Owen, W. Suk, and U. Unluata. 2002. Indicators of ocean health and human health: A research framework. Environmental Health Perspectives 110:839-845.

Kovats, S., J.A. Patz, and D. Dobbins. 1998. Global climate change and environmental health: proceedings of the 1997 annual conference of the Society for Occupational and Environmental Health. International Journal of Occupational and Environmental Health 4(1):41-52.

National Research Council (NRC). 1999. From Monsoons to Microbes: Understanding the Oceans Role in Human Health. National Academy Press, Washington, D.C.
Pew Oceans Commission. 2003. America's Living Ocean: Charting a Course for Sea Change. [Online] Available at: http://www.pewtrusts. org/pdf/env_pew_oceans_final_report.pdf [last accessed March 23, 2006].

Sandifer, P.A., A.F. Holland, T.K. Rowles, and G.I. Scott. 2004. The oceans and human health. Environmental Health Perspectives. 112(8): A454-455.

Stegeman, J.J, A.R. Solow, and T.J. Goehl. 2002. Environmental health and the coastal zone. Environmental Health Perspectives 110(11): A660-661.

Tibbetts, J. 2002. Coastal cities: Living on the edge. Environmental Health Perspectives 110(11): A674-681.

Tibbetts, J. 2005. America's oceans: A blueprint for the future. Environmental Health Perspectives 113(2):A106-109.

Tyson, F.L., D.L. Rice, and A. Dearry. 2004. Connecting the oceans and human health. Environmental Health Perspectives 112(8):A455-456.

U.S. Commission on Ocean Policy. 2004. An Ocean Blue Print for the $21^{\text {st }}$ Century. [Online] Available at: http://www.oceancommission.gov/documents/full_color_rpt/000_ocean_full_report. pdf [last accessed March 20, 2006]. 